\title{
Seroprevalence of Dengue from a Tertiary Care Hospital in South India
}

Marie Victor Pravin Charles*, Ramakrishnan Kalaivani, Arunava Kali and Kunigal Sreenivasiah Seetha

Department of Microbiology, Mahatma Gandhi Medical College and Research Institute, Puducherry, India

\begin{abstract}
Dengue is a mosquito borne viral fever transmitted by Aedes aegypti and albopictus mosquito. The globally estimated burden of symptomatic cases ranges to 96 million and 58.4 million cases/year). The estimated mortality amounts $2.5 \%$ and the endemicity is spread around 128 countries of the world. The aim of our study is to identify the prevalence of dengue to the patients reporting to our tertiary care hospital in Puducherry. A prospective crosssectional study was conducted at our tertiary care hospital in Puducherry. The study was conducted over a period of 4 years from January 2013 to December 2016. The serum samples were tested by Rapid immunochromatography test. Around $272(12.3 \%)$ cases of both primary and secondary dengue were identified. The age wise distribution of cases showed more cases in 21 to 30 age group (38.6\%). The seasonal distribution shows more cases were present from September to January. There was a gradual increase in the positive cases from 2013 onwards with a peak during 2016. Being a persistent viral infection a proper vector control measure, concomitant monitoring on the Seroprevalence of dengue among the population is needed.
\end{abstract}

\section{Keywords: RICT; NS1 antigen}

\section{Introduction}

Dengue virus is a single stranded positive sense RNA virus belonging to the genus flavivirus. The globally estimated burden of symptomatic cases ranges to 96 million and 58.4 million cases/year [1].

Dengue virus has 5 different serotypes whose immunity being serotype specific [2]. Dengue has a spectrum of disease including undifferentiated fever, dengue fever, and dengue hemorrhagic fever. According to the 2009 World Health Organization (WHO) classification dengue is divided into uncomplicated and severe groups [3]. The estimated mortality amounts $2.5 \%$ and the endemicity is spread around 128 countries of the world, however the epidemic outbreak is more common during the rainy season when the vector population is more [4].

In 1780 the first epidemic of clinical dengue cases was reported from Chennai in India. Since then dengue has been reported from various parts of the country. In 1996 a widespread epidemic of dengue was reported in Delhi and Lucknow disseminating all over the country [5]. All the five serotypes are prevalent causing epidemics in India now and then.

Early diagnosis of dengue among the population is crucial to alert the prevention strategies before the epidemic begins. It also aids the clinicians to commence appropriate treatment at an early stage.

\section{Materials and Methods}

\section{Study design}

A prospective cross-sectional study was conducted at our tertiary care hospital in Puducherry. The study was conducted over a period of 4 years from January 2013 to December 2016. The study included all patients with fever who were clinically suspected for dengue. The WHO criterion for diagnosis of dengue was followed by our clinicians. Around 2200 samples from patients were sent to our laboratory for dengue diagnosis. This study was submitted at the institutional human ethics committee and approval was obtained. Informed consent was obtained from patients who were involved in the study.

\section{Sample collection}

Blood was collected from all patients who were suspected for dengue. Around 1-2 ml pf blood was collected from the patients following sterile precautions. The blood was allowed to clot for 20 minutes at the end of which the samples were centrifuged and serum was separated.

Rapid immuno-chromatography test (RICT) (SD BIOLINE DENGUE DUO KIT): The serum samples were screened for NS1 Antigen, IgM and IgG antibodies by the rapid card test. The RICT consists of two cassettes, one for antigen detection and another for antibody detection. The serum samples were placed in the sample window of each cassette. The kit had a detection time of $20 \mathrm{mins}$ at the end of which the results were obtained. The test band was compared with the control band and the positive result was obtained.

\section{Statistical analysis}

The variables were analyzed by percentage. Chi-square test was used for testing the homogeneity of age and year distribution of dengue cases. The seasonal variation in the distribution of cases was detected using time series analysis (seasonal variation by the method of simple average). Seasonal variation index was calculated.

\section{Results}

A total of 2200 samples from patients with suspected dengue were sent to our laboratory. Around 272 (12.3\%) cases of both primary and secondary dengue were identified. The year wise distribution of positive cases is shown in Table 1. The age wise distribution of cases showed more cases in 21-30 age group (38.6\%). The least number of cases were above 60 years $(2.5 \%)$. The seasonal distribution shows more cases were present from September to January. The time series analysis shows that

*Corresponding author: Marie Victor Pravin Charles, Department of Microbiology, Mahatma Gandhi Medical College and Research Institute, Puducherry, India, Tel: 9952791982; E-mail: dr_mvpravincharles@yahoo.com

Received June 25, 2018; Accepted July 15, 2018; Published July 18, 2018

Citation: Charles MVP, Kalaivani R, Kali A, Seetha KS (2018) Seroprevalence of Dengue from a Tertiary Care Hospital in South India. J Med Microb Diagn 7: 279. doi:10.4172/2161-0703.1000279

Copyright: @ 2018 Charles MVP, et al. This is an open-access article distributed under the terms of the Creative Commons Attribution License, which permits unrestricted use, distribution, and reproduction in any medium, provided the original author and source are credited. 
Citation: Charles MVP, Kalaivani R, Kali A, Seetha KS (2018) Seroprevalence of Dengue from a Tertiary Care Hospital in South India. J Med Microb Diagn 7: 279. doi:10.4172/2161-0703.1000279

Page 2 of 3

\begin{tabular}{|c|c|c|c|c|}
\hline Year & Total number of samples & Number of dengue positive & Percentage & P-value \\
\hline 2013 & 443 & 58 & $7.09 \%$ \\
\hline 2014 & 278 & 22 & $14.7 \%$ \\
\hline 2015 & 733 & 108 & $11.2 \%$ \\
\hline 2016 & 746 & 84 & $12.36 \%$ \\
\hline Total & 2200 & 272 & 0.0191 \\
\hline p-value $<0.05$ which is statistically significant. & & \\
\hline
\end{tabular}

Table 1: Year wise distribution of positive cases.

\begin{tabular}{|c|c|c|}
\hline Age in years & Positive cases & Percentage \\
\hline $1-10$ & 26 & $9.5 \%$ \\
\hline $11-20$ & 45 & $16.5 \%$ \\
\hline $21-30$ & 105 & $38.6 \%$ \\
\hline $31-40$ & 54 & $19.85 \%$ \\
\hline $41-50$ & 25 & $9.9 \%$ \\
\hline $51-60$ & 10 & $3.6 \%$ \\
\hline$>60$ & 7 & $2.5 \%$ \\
\hline p-value is significant which means the disease affected in the age group of $21-30$ is higher than the other groups
\end{tabular}

p-value is significant which means the disease affected in the age group of 21-30 is higher than the other groups

Table 2: The age wise distribution of positive cases.

\begin{tabular}{|c|c|c|c|c|c|}
\hline Month & 2013 & 2014 & 2015 & 2016 & $\begin{array}{c}\text { Seasonal variation index } \\
\text { (SVI) }\end{array}$ \\
\hline January & 4 & 6 & 0 & 12 & 103.18 \\
\hline February & 3 & 2 & 3 & 6 & 49.86 \\
\hline March & 0 & 2 & 2 & 10 & 84.24 \\
\hline April & 3 & 1 & 0 & 5 & 23.22 \\
\hline May & 0 & 1 & 1 & 1 & 21.61 \\
\hline June & 3 & 4 & 1 & 6 & 74.18 \\
\hline July & 9 & 1 & 1 & 8 & 65.39 \\
\hline August & 3 & 1 & 5 & 8 & 52.87 \\
\hline September & 4 & 2 & 14 & 7 & 136.96 \\
\hline October & 15 & 2 & 15 & 10 & 150.60 \\
\hline November & 14 & 0 & 31 & 9 & 246.73 \\
\hline December & 11 & 0 & 35 & 2 & 191.15 \\
\hline Total & 58 & 22 & 108 & 84 & 1200 \\
\hline
\end{tabular}

Table 3: Seasonal variation of dengue cases.

the highest number of cases was found during the month of November. There was a gradual increase in the positive cases from 2013 onwards with a peak during 2016. The age wise distribution of positive cases is shown in Table 2. Out of the positive cases obtained the seasonal variation is shown in Table 3 . The positive cases were categorized based on the appearance of NS1 Ag, IgM and Ig G antibodies. The distribution of positive cases is shown in Table 4 .

\section{Discussion}

Dengue is notorious to cause serious infection and life-threatening complications. The diagnostic modalities include virus isolation, RNA detection, NS1 antigen detection and IgM or IgG antibody detection [6]. However there are technical hitches in utility of these tests. Ig $\mathrm{M}$ and Ig G antibody detection tests which are used in acute primary and secondary infections can cross react with other flavivirus group and yield a false positive result [7]. On the contrary NS1 antigen being specific for dengue does not cross react with other flavivirus group excluding the secondary cases where immune complex formation occurs [8]. RICT compared to ELISA are easy to perform and detect the infection earlier [9]. It aids in immediate treatment and curbs the mortality. In addition, the combination of NS1, Ig M \& Ig G increases the sensitivity of these rapid kits [10]. The utility of RICT has been evaluated by various studies around the world. In a study from South India it is shown that RICT has sensitivity and specificity with $95.4 \%$ and $98.33 \%$ respectively in comparison with PanbioELISA [9]. Similar studies by Andries, et al. and Blacksell, et al. showed a sensitivity of $85 \%$ and $92 \%$ respectively $[11,12]$. Wang SM and coworkers reported the specificity of RICT as $98 \%$ [13]. In our study there is a gradual increase in the Seroprevalence of dengue over the years from 2013 to 2016. The positivity rate was high in 2015 (14.7\%) which was statistically significant with p value $<0.05$. The reason for this increase in cases during the year 2015 could be due to increase in rainfall promoting mosquito breeding. The most affected age group was 21-30 (38.6\%) followed by 31-40 (19.85\%) which is like the other studies done in India [14]. The age distribution was statistically significant with $\mathrm{p}$ value $<0.05$. The distribution of positive cases was more from September to January which is like the other studies [15]. The time series analysis showed that the seasonal variation index was high during the month of November (246.73) which very high compared to the average during the month of May (21.61) (Figure 1). This shows the increase in dengue is associated with the breeding pattern of the mosquitos. The drawback of our study was that ELISA was not done, however with the specificity of $98 \%$ and $100 \%$ of the earlier studies reported the chance of reporting a false positive dengue case is very meagre. Being a cost effective and easy to perform test RICT is a better alternative in resource poor settings and rural areas. 
Citation: Charles MVP, Kalaivani R, Kali A, Seetha KS (2018) Seroprevalence of Dengue from a Tertiary Care Hospital in South India. J Med Microb Diagn 7: 279. doi:10.4172/2161-0703.1000279

Page 3 of 3

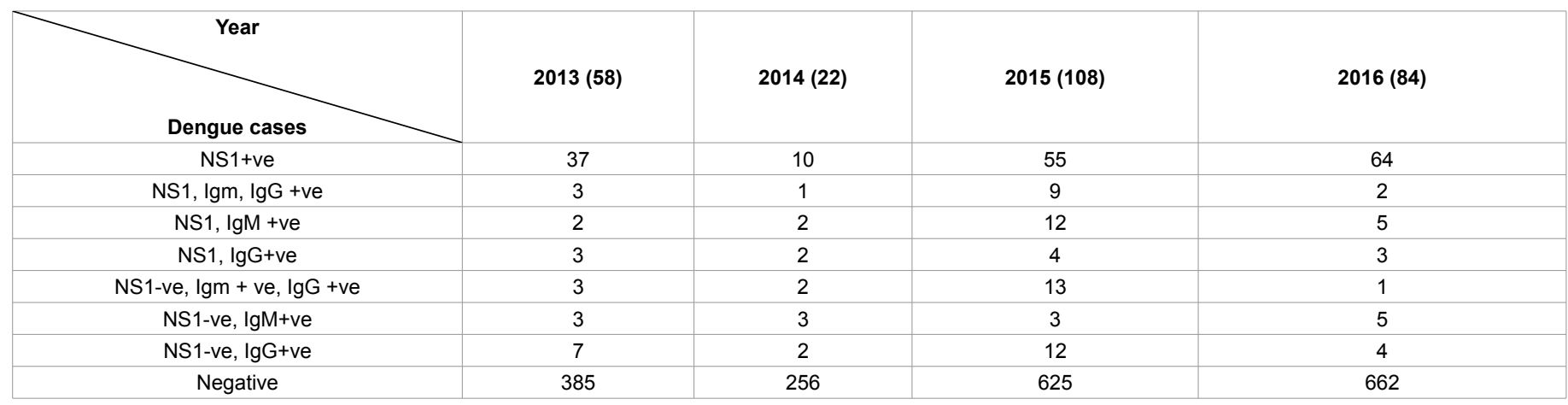

Table 4: Distribution of positive cases.

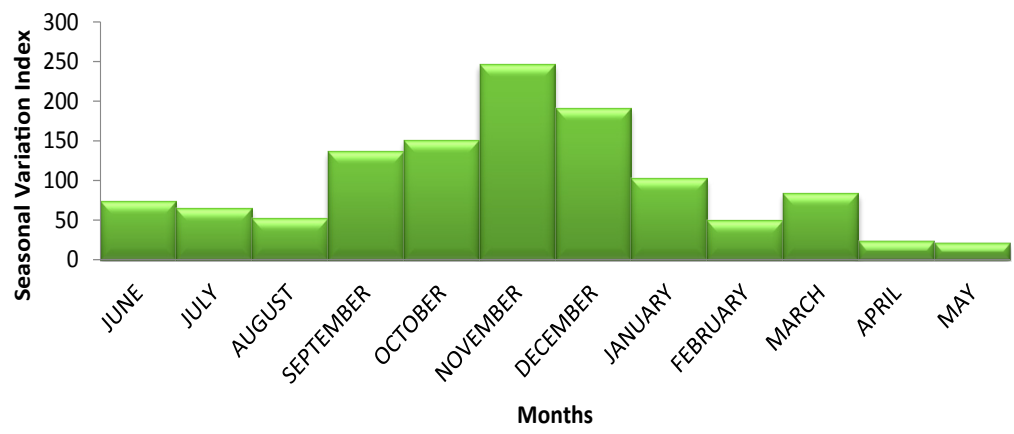

Figure 1: Seasonal variation index of positive cases.

\section{Conclusion}

Dengue being a persistent viral infection in the Indian subcontinent, it causes seasonal epidemics with increase in mortality. There should be a proper vector control measure, concomitant monitoring on the Seroprevalence of dengue among the population, so that further outbreaks could be prevented.

\section{Acknowledgement}

The authors appreciate the contribution of Sri Balaji Vidyapeeth University for their financial support.

\section{References}

1. Prayitno A, Taurel AF, Nealon J, Satari HI, Karyanti MR, et al. (2017) Dengue seroprevalence and force of primary infection in a representative population of urban dwelling Indonesian children. PLoSNegl Trop Dis 11: e0005621.

2. Ashshi AM (2015) Sero-detection of dengue virus and its antibodies among blood donors in the western region of Saudi Arabia: A preliminary study. Blood Transfus 13: 135-138.

3. Whitehorn J, Farrar J (2010) Dengue. Br Med Bull 95: 161-173.

4. Ayukekbong JA, Oyero OG, Nnukwu SE, Mesumbe HN, Fobisong CN (2017) Value of routine dengue diagnosis in endemic countries. World J Virol 6: 9-16.

5. Shah I, Deshpande GC, Tardeja PN (2004) Outbreak of dengue in Mumbai and predictive markers for dengue shock syndrome. J Trop Pediatr 50: 301-305.

6. Sharma Y, Kaur M, Singh S, Pant L, Kudesia M, et al. (2012) Seroprevalence and trend of dengue cases admitted to a Government hospital, Delhi- 5-year Study (2006-2010): A look into the age shift. Int J Prev Med 3: 537-543.

7. Lapphra K, Sangcharaswichai A, Chokephaibulkit K, Tiengrim S, Piriyakarnsaku W, et al. (2008) Evaluation of an NS1 antigen detection for diagnosis of acute dengue infection in patients with acute febrile illness. Diagn Microbiol Infect Dis 60: 387-391

8. Falconar AK, Young PR, Miles MA (1994) Precise location of sequential dengue virus sub complex and complex B cell epitopes on nonstructural 1 glycoprotein Arch Virol 137: 315-326.

9. Stephen S, Charles MP, Anitharaj V, Deepa C, Umadevi S (2014) Early dengue diagnosis by nonstructural protein 1 antigen detection: Rapid immunochromatography versus two the enzyme-linked immunosorbent assay kits. Indian J Pathol Microbiol 57: 81-84.

10. Prado PS, Almeida JTD, De Abreu LT, Silva CG, Souza LDC, et al. (2018) Validation and reliability of the rapid diagnostic test 'SD Bio-easy Dengue Duo' for dengue diagnosis in Brazil: A phase III study. Mem Inst Oswaldo Cruz 113: e170433.

11. Andries AC, Duong V, Ngan C, Ong S, Huy R, et al. (2012) Field evaluation and impact on clinical management of a rapid diagnostic kit that detects dengue NS1, IgM and IgG. PLoS Negl Trop Dis 6: el993.

12. Blacksell SD, Jarman RG, Bailey MS, Tanganuchitcharnchai $A$, Jenjaroen $K$, et al. (2011) Evaluation of six commercial point-of-care tests for diagnosis of acute dengue infections: The need for combining NS1 antigen and IgM/IgG antibody detection to achieve acceptable levels of accuracy. Clin Vaccine Immunol 18 2095-2101.

13. Wang SM, Sekaran SD (2010) Early diagnosis of dengue infection using a commercial Dengue Duo rapid test kit for the detection of NS1, IGM, and IGG. Am J Trop Med Hyg 83: 690-695.

14. Gupta E, Dar L, Narang P, Srivastava VK, Broor S (2005) Sero-diagnosis of dengue during an outbreak at a tertiary care hospital in Delhi. Indian J Med Res 121: 36-38.

15. Padhi S, Dash M, Panda P, Parida B, Mohanty I, et al. (2014) A three-year retrospective study on the increasing trend in seroprevalence of dengue infection from southern Odisha, India. Indian J Med Res 140: 660-664. 